\title{
Preservice Teachers' Perception of Plagiarism: A Case from a College of Education
}

\author{
Michael H. Romanowski ${ }^{1}$ (D)
}

Accepted: 24 January 2021/Published online: 21 April 2021

(c) The Author(s) 2021

\begin{abstract}
Few studies examine plagiarism in a Middle Eastern context, specifically from the perspectives of preservice teachers. As future gatekeepers of academic integrity, preservice teachers need to understand plagiarism. This study surveyed 128 female preservice teachers in one university in the Gulf Cooperation Council (GCC) countries. The survey explores preservice teachers regarding their understandings and reasons for academic plagiarism and their responses to particular scenarios. Findings indicate that preservice teachers have a thorough comprehension of plagiarism and suggest a lack of knowledge of citing sources, weak writing skills, a lack of time, and not knowing the research process as reasons for plagiarism. Informants' responses to six scenarios are presented to illustrate their perspectives further. Discussion addresses language and cultural issues to contextualize the study.
\end{abstract}

Keywords Plagiarism · Preservice teachers · Gulf cooperation council countries · Teacher education

\section{Introduction}

Plagiarism is not a new phenomenon (Scanlon, 2003). Gullifer and Tyson (2014) state that "research has established that the term plagiarism is open to different interpretations, resulting in confusion among students and staff alike" (p. 1202). Gibaldi (2003) suggests there is little agreement on exactly how plagiarism is defined, but there is a consensus that plagiarism is using another person's ideas, work, and expression and passing it off as one's ideas, work, and expression. Maxel (2013) states,

despite the differences of the versions and definitions of plagiarism... the general agreement about plagiarism is that it occurs when the materials that have been produced lack originality, poor citation of materials used, non-obtainment of permission from the original authors extension of materials of others without acknowledgment, use of texts, figures and any other unique materials that are not original (p. 137).

Michael H. Romanowski

michaelhr@qu.edu.qa

1 Educational Research Center, College of Education, Qatar University, Doha, Qatar 
For this study, plagiarism is the misappropriation of others' work, whether published or non-published, without proper acknowledgment (Gilbert \& Denison, 2003). However, plagiarism can either deliberate or accidental and it does not follow that plagiarism is always cheating since cheating is a deliberate and dishonest act. McCuen (2008) states, "most acts of plagiarism are likely acts of ignorance rather than intended acts of deception or fraud" (p. 152).

Studies investigating plagiarism generally report increases (Choo \& Paull, 2013; TorresDiaz et al., 2018) and a growing concern that plagiarism is becoming much more prevalent in higher education systems worldwide (Yeo, 2007; Zobel \& Hamilton, 2002). Access to information technology has made plagiarism easier and is considered as the reason for the increase in plagiarism (Ashworth, Freewood \& Macdonald, 2003; Hansen, 2003; Ison 2014). More importantly, plagiarism conflicts with higher education goals and is a grave threat to academia (Lim \& See, 2010). Howard (2007) states,

plagiarism in the academy matters so dearly because writing assignments are intended to help students learn course materials and gain communication and thinking skills. If those assignments are undermined through plagiarism, neither learning takes place, and the academic enterprise is itself endangered (p. 11).

There is an assortment of types of plagiarism including but not limited to (Habibzadeh \& Shashok, 2011), text (Bakhtiyari et al., 2014), self-plagiarism (Martin, 2013; Risquez, 2013) and paying someone else to write a paper (Menezes et al., 2014). Nevertheless, an understanding and the ability to acknowledge sources to avoid plagiarism is vital at the university level because students are required to present their thoughts and work by researching and synthesizing ideas from scholarly sources within their work (Gullifer \& Tyson, 2010).

Although important for all university students, it could be argued that understanding plagiarism is vital for education students (preservice teachers) because they become the gatekeepers of academic honesty in their future roles as teachers. With that in mind, this study investigates preservice teachers' understandings of plagiarism. In what follows, the concept of plagiarism is defined and discussed before presenting findings from surveying 130 undergraduate education majors' students attending a University in the Gulf Cooperation Council (GCC) country. Finally, several recommendations are posited to inform university students about plagiarism.

\section{Literature Review}

\section{Technical Influences on Plagiarism}

According to Gullifer and Tyson (2014), there are many reasons for plagiarism linked to technical, cultural, and social factors. For undergraduates, the technical aspects of writing often confused them about what comprises plagiarism since they often lack an understanding of how to reference sources of information (Ashworth et al., 1997; Jackson, 2006). Madray (2007) states,

Most students want to complete their research assignments honestly but find it difficult, simply because they are clueless about accomplishing it. Doing research is an involved and detailed process that requires the ability to find, analyze, and synthesize information while applying the appropriate rules of grammar and citation. The concept of interpreting and implementing the rules of plagiarism - to take information from varied sources and knead 
it into one's own research writing-proves to be challenging and confusing for students (Conclusion section, para. 2).

Schrimsher et al. (2011) found that students in their early years in college are overwhelmed with the complexity of research assignments coupled with the desire for completion that enables inadvertent plagiarism.

Pennycook (1996) refers to students' poor study skills that are pressured under heavy workloads. Additional reasons are students' poor note-taking skills that lead to confusion, the inability to distinguish between personal material, and what material came from other sources (Breen \& Maassen, 2005; Harris, 2000). Also, students' inability to understand new or unfamiliar terms (Roig, 1999) and their previously acquired learning strategies have not taught them to utilize academic resources correctly (Howard 1995).

Previous research has indicated that particular demands placed on students might cause intentional plagiarism. Ashworth et al. (1997) argue that students cope with the demands of studying and securing good grades by plagiarizing. Graham et al. (1994) found that the number-two reason students plagiarize is that they do not have sufficient time. Overcommitted students often plagiarize out of desperation (Zobel \& Hamilton, 2002).

\section{Cultural and Social Influences on Plagiarism}

There are some researchers who report that cultural differences can contribute to understandings and reasons of plagiarism (Chien, 2014; Farisi, 2013; Moten, 2014; Razek, 2014). Studies have indicated that in most countries, students admit to plagiarizing and did not regard 'cut-and-paste' as a serious issue. They copied text from the Internet and used it without citation (McCabe, 2005; Scanlon \& Neumann, 2002; Szabo \& Underwood, 2004). Pupovac et al. (2008) found a high rate of student plagiarism in four different European countries: Spain, the UK, Bulgaria, and Croatia. Comparable results have been demonstrated in the Asian (Chun-Hua \& Ling-Yu, 2007) and African countries (Teixeira \& Rocha, 2010).

Researchers suggest that cultural differences can have a significant effect with regard to understandings and reasons for plagiarism (Adiningrum \& Kutieleh, 2011; Chien, 2014; Razek, 2014). Over the past few decades have witnessed a shift in the perception of plagiarism in education that acknowledges the cultural complexity and dependency of plagiarism (Maxwell et al., 2008). The shift begins to address understanding plagiarism by considering the influences that affect behavior, including cultural factors (Egan, 2008; Stappenbelt et al., 2009). Fawley (2007) argues that when addressing plagiarism, one must consider the relevant cultural differences, including different educational philosophies, previous academic experiences, and individual cultural differences. Pennycook (1996) states, "students come to our classes with different cultural and educational backgrounds, with different understandings of texts and language, with different approaches to learning" (p. 226). Non-Western students hold different understandings of ownership of academic work. Memorization is considered a valuable and useful way of learning in Asian societies (Pennycook, 1996), and copying can help to develop writing skills among many international students (McDonnell, 2004).

Furthermore, in some Asian countries, there are hierarchical structures that consider it wrong to repeat or change the words of scholars (Hafernik et al., 2002; Chien, 2014). These students value the source with the highest authority, but they do not believe in citing their sources as expected in Western society (Duff et al., 2006). Being critical of sources is viewed as a sign of disrespect (Pecorari, 2003). Some cultures do not consider omitting 
citations as plagiarism (Adiningrum \& Kutieleh, 2011). In collective cultures, the view is that knowledge belongs to the society itself, and it is less important to credit sources (Chien, 2014; Hofstede, 2011). Finally, in many cultures, grades and results receive more value than the learning process (Lahur, 2004), creating situations where students are more likely to plagiarize instead of learning to secure good grades. As for the social factors that lead might to plagiarism, Jereb et al. (2018) found that family and societal pressures of getting high grades are essential factors that influence plagiarism. Additionally, peer culture and peer pressure can play a role in student plagiarism (Hosny \& Shameem, 2014; Ma et al., 2008).

\section{Middle Eastern Countries, Culture and Plagiarism}

Heitman and Litewka (2011) found that plagiarism is more common in developing nations. Developing nations like the GCC countries have become more open to Westernization, evident in changes in attitudes toward plagiarism in these countries (Ayub et al., 2014). Concerning plagiarism in the Arab world, several studies examine Saudi Arabian students and plagiarism. Hamdan et al. (2018) reported that Saudi Arabian students plagiarize because of the heavy project loads, the lack of checking for plagiarism by instructors, and students' lack of sufficient knowledge about avoiding plagiarism. Razek (2014) examined 673 Saudi university students studying in the US about academic integrity, including plagiarism. The findings reported large differences in academic misconduct between Saudi students and US students but no significant difference between students in other Middle Eastern Countries and those in the US. Razek reported that for Arab students, plagiarism appeared to be a common practice justified as an acceptable norm for academic survival. Findings reported a gap between their own cultural, religious, and ethical beliefs and plagiarism.

Hosny and Shameem (2014) surveyed 115 Saudi female college students about plagiarism and found that plagiarism was common. They found that $72.1 \%$ of the students knew what plagiarism means. The respondents reported (11\%) that they submitted someone else's work. Others (32\%) reported changing words without using references, and $40 \%$ reported using exact words. Also, they reported that students considered plagiarism as less severe an act of dishonesty even though most thought it was unethical and against their religion. Riasati and Rahimi (2013) conducted a qualitative study in Iranian universities. They reported that student plagiarism included a shallow understanding of plagiarism, limited language skills, modest research and writing skills, and the cultural factors of family and societal pressures.

Nuriddin (2019) examined Saudi students' perceptions of academic dishonesty and reported that academic dishonesty was prohibited based on personal beliefs and Islamic values, with several quoting a Hadith that professed anyone who cheated was not a member of the Islamic community. Still, these respondents admitted engaging in academic dishonesty. However, for these participants, academic misconduct was not quite merely black and white. On the one hand, they acknowledge plagiarism was unaccepted in Islam. On the other hand, Islamic values of empathy, helpfulness, and Islamic duty to help a friend are also important. Nuriddin (2019) points out that students compartmentalized their behavior using it to rationalize academic dishonesty as helping others, a critical Islam value, and also reflects Saudi's collective society. The views of plagiarism and cheating in well-established collectivistic societies and values of honor and shame found in Middle 
Eastern cultures can influence students' perceptions and understandings of plagiarism (Chapman \& Lupton, 2004; Cinali, 2016; McCabe et al., 2008). Together, these studies indicate that students still engage in plagiarism regardless of cultural background and value systems (Cinali, 2016).

\section{Teachers and Preservice Teachers and Plagiarism}

Regarding preservice and in-service teachers, Chen and Ku (2012) found that over 90\% of Taiwanese teachers in their study consider text plagiarized when copied without citations. However, when citations were provided, fewer participants considered the text plagiarized. The authors point out that only $43 \%$ of participants viewed changing the order of sentences and providing citations as plagiarism. Only $26 \%$ thought that changing words and preserving the original sentence structure but providing citations was plagiarism. The overall findings suggested that if the citation is used, borrowing or copying text verbatim was not an act of plagiarism.

Seven and Engin (2008) researched students/teacher candidates in a College of Education in Turkey. They reported that most teacher candidates believe that they needed to plagiarize. Asunka (2012) studied preservice teachers in Ghana enrolled in an online educational technologies course. All participants possessed a fair understanding that plagiarism was an undesirable practice. Although all students heard of plagiarism, they had varied definitions and different understandings of what constituted plagiarism. Also, all participants had a fair understanding of plagiarism. Eret and Ok, (2014) examined teacher candidates in Turkey and found that they tended to plagiarize materials from the Internet or hand in assignments from different courses. Concern Middle Eastern and GCC countries, very few, if any studies have examined preservice teachers' understandings of plagiarism. It is important to examine preservice teachers' perceptions of plagiarism since these could shape their students' views of plagiarism. As future gatekeepers of academic integrity, it is essential to gain insight into how they understand plagiarism.

\section{The Study}

\section{Research Questions}

This exploratory and descriptive study utilizes a mixed-method survey approach that examines preservice teachers' understandings of plagiarism. The research utilizes survey research to collect data regarding preservice teachers' understanding of plagiarism. The study had four questions:

1. What are preservice teachers' understandings of plagiarism.

2. From preservice teachers' perspectives, do preservice teachers plagiarize and if so, why?

3. What knowledge do preservice teachers believe they possess regarding plagiarism?

4. How do preservice teachers' respond to particular plagiarism scenarios?

A questionnaire containing both open and closed questions was developed to assess what informants know about plagiarism and apply it to particular scenarios. The first five questions request for demographic information and one open question asking, why do you think some students plagiarize? Ten closed questions are included in the questionnaire taken from the Student Authorship Questionnaire (SAQ) developed by Pitman et al. (2009) 
to examine psychology students' beliefs about authorial identity in academic writing and based on nine constructs identified by a review of the literature on student authorship and plagiarism (Pittam et al., 2009). The Student Authorship Questionnaire has been used examine students and their beliefs about authorship in several other studies with accounting undergraduate students and first years nursing students in Irish universities (Ballantine et al., 2015; Maguire et al., 2013), Taiwanese undergraduates (Cheung et al., 2017), students studying accounting and business in China (Ballantine et al., 2015), dyslexic and non-dyslexic university students (Kinder \& Elander, 2012).

The SAQ was adapted to replace 'psychology' with 'education' and seven questions were omitted. Several omitted items addressed authorial identity that was deemed irrelevant for the purpose of this study and three were eliminated to reduce the size of the questionnaire since scenarios would be added. These questions require respondents to indicate their acceptance using a five-point Likert scale anchored with 'strongly agree' and 'strongly disagree.' Sample statements include: "I find it difficult to express education concepts in my own words;" "I know how to show which parts of my assignments were not written by me;" and "I get higher marks by writing more of my assignment in my own words."

The remaining questions on the survey include six individual scenarios selected based on the adapted from Avoiding Plagiarism: Scenarios (2015) and contextualized to fit this particular culture. Each scenario requires the informants to tell Why this is or is not plagiarism, and if they consider this plagiarism, how serious do you think this is? See Appendix A for examples of the scenarios. The questionnaire was initially written in English then translated into Arabic and assessed for the quality of the translations by bilingual native Arabic speakers. Face validity was obtained by having two bilingual professors examine the questionnaire and determine if the Arabic version was accurately asking informants to discuss their understanding of the concept of plagiarism.

The questionnaire was posted on Survey Monkey in Arabic and English. Regarding the exploratory nature of the study, both closed and open-ended questions were appropriate for this research. While closed questions allow the data to be analyzed statistically and yield generalizable results, the narrative comments from open-ended questions provide a forum for explanations, meanings, and new ideas to describe a phenomenon as lived and perceived by the respondent (Cohen et al., 2007). Emails were sent to all undergraduates in the College of Education, and professors who taught courses with undergraduates enrolled were asked to mention the survey to their students.

The survey first asked informants to list their current university status. Informants were then asked to write their understanding of the concept of plagiarism and state if they read the undergraduate handbook regarding plagiarism. They were also asked to list reasons students plagiarize, followed by a series of questions that require self-assessment regarding their ability to cite references, confidence, ability and approach to expressing academic concepts and ideas (see Appendix A). The informants were then asked to respond to six scenarios where they determine if plagiarism has occurred, write a supporting statement for their response, and, if considered plagiarism, determine the seriousness of the offense on a threepoint rating scale. The research study received IRB approval from the appropriate university.

\section{Context and Sample}

As was discussed earlier, this study was carried out at one particular university in the GCC. Unlike most university students, preservice teachers are more inclined to address plagiarism during their university teacher education courses since some assessment courses 
and other include concerns about plagiarism. As previously mentioned, preservice teachers will be dealing with plagiarism in their future careers as teachers.

The university enrolls over 14,000 students from around the world, predominately from Arab nations and the College of Education enrolls 1300 students, 1240 females and 60 males. Within the past five years, the university was ranked by the Times Higher Education World University Rankings as the world's most international universities 2016. All instructors in the College of Education teaching an introduction to research were asked to request that all preservice teachers in their class respond to the survey posted on Survey Monkey. The sample in this study included 128 females enrolled in various undergraduate teacher education programs. Although a small sample, the sample was representative of the college since it incorporated preservice from all levels (primary, middle, and secondary) and a wide variety of majors. Given the small number of males in the preservice teacher program and the few responses received, only female respondents were included in this study. Specifically, the sample included 13 s-year students, 78 third-year students, and 37 fourth-year students in the college. Second, third- and fourth-year students were targeted since students in their first semester could easily be unaware of plagiarism in general and its seriousness in particular since they lack experience studying at the university.

To illustrate, the undergraduate catalog at the university where this study was conducted gives examples of plagiarism similar to most universities that include, "The use of the work, ideas, images or words of someone else without his/ her permission; use of someone else's wording, name, phrase, sentence, paragraph or essay without using quotation marks and misrepresentation of the sources that were used." Having received accredited status from the National Council for Accreditation of Teacher Education, the College of Education (CED) is required to make deliberate efforts to enhance academic honesty. These efforts involve placing a definition of plagiarism on the syllabus for every course taught within the college. There is no requirement of faculty to instruct or discuss issues of academics honestly and plagiarism beyond including the statement of "plagiarism is the act of taking the words or ideas of another and representing them as one's own" on all syllabi used in the CED. Being exposed to the CED's policy of academic honesty, the following sections survey preservice teachers' understandings and perceptions of academic plagiarism and how they apply them to their academic work. Before that, the reasons and causes that lead to plagiarism, as were established and discussed in the existing literature were reviewed.

At this point, it is important to note that these preservice teachers selected themselves to participate in this study. Thus, self-selection bias could be a concern since students who possess more knowledge about plagiarism, who are more conscientious, and those who tend to be better students might be the ones who complete the survey. This bias can lead to wrong conclusions since these findings may not be representative of all these preservice teachers. Therefore, this bias should be considered, and results may be viewed as typical of preservice teachers who are more knowledgeable than other students about plagiarism.

\section{Data Analysis}

The data analysis involved two processes. First, the quantitative data were assigned to two groups, and informants' responses to each of the ten Likert scale questions were analyzed using Chi-square. Second, the responses to the open-ended questions on the survey that were written in Arabic were translated to English then placed into NVivo for analysis. The data analysis was conducted utilizing the research objectives as a 
framework to examine Informants' understanding of plagiarism. Through inductive analysis, various themes emerged and were organized around the categories that were derived from the data itself. The rationale for the entire process was to provide an account of CED's preservice teachers' understanding of plagiarism, as the section below elaborates further.

\section{Findings}

\section{Informants' Understandings Plagiarism and Why Students Plagiarize}

Concerning informants understanding of plagiarism, ninety-seven percent informants' short written responses were aligned with at least one or more aspects of the university's definition and the College of Education's statement on plagiarism. In the written responses, informants expressed their understanding of plagiarism with terms such as "take," from a source (35\%) "steal" (19\%), or "copy" (18\%). Only 3\% of the informants were unaware of the term plagiarism. Table 1 illustrates how informants understood plagiarism, the percentage of informants who provided this understanding and phrases used by informants in their short written responses.

Regarding the reasons why students plagiarize, Table 2 provides the informants' responses when asked why students plagiarize. These reasons range from a lack of knowledge of how to effectively document academic writing, difficulties in writing and particular skills needed to write to personal reasons such as laziness.

\section{Informants' Perceptions About Academic Writing and Referencing}

The sample was assigned to two groups, senior students (4th years; $n=37$ ) and second the group comprising the remainder of the students ( 2 nd and 3rd years, $n=91$ ). Informants' responses to each of the ten Likert scale questions were analyzed using Chi-square. This exploratory and descriptive study was designed to assess differences in responses between the two groups. The 5 item Likert scale responses were combined into two categories (Strongly Agree/Agree and Strongly Disagree/Disagree with "Neutral" responses excluded from the analysis), and a Chi-square test was used to assess the relationship between academic year and knowledge of plagiarism (see Boone $\&$ Boone, 2012). The Likert scale questions were constructed to assess the Informants' academic knowledge and skills in writing academic papers. The statistical analysis of the responses found that only two of the ten questions elicited statistically significantly differences between the two groups, specifically, question $2, x^{2}(1, \mathrm{~N}=125)=11.46$, $\mathrm{p}<0.01$ and question $10, x^{2}(1, \mathrm{~N}=124)=8.40, \mathrm{p}<0.01$. When the responses to all questions in the ten-item Likert scale questions were combined and analyzed, it was found that there was a statistically significant difference in the responses between the two groups, $x^{2}(1, \mathrm{~N}=125)=86.12, \mathrm{p}<0.01$. These findings indicate that $4^{\text {th }}$-year students, compared to 2 nd and $3^{\text {rd }}$-year students, express more confidence in their ability to write and properly reference their papers. Table 3 illustrates descriptive statistics for questions 2 and 10. 
Table 1 Understandings of Plagiarism

\begin{tabular}{|c|c|c|}
\hline Understanding Plagiarism & Percentage of Informants & Phrases used to Define Plagiarism \\
\hline $\begin{array}{l}\text { Ownership and claiming others work as } \\
\text { your own }\end{array}$ & $72 \%$ & $\begin{array}{l}\text { - without mentioning the author's } \\
\text { name } \\
\text { - copying work without naming } \\
\text { the source } \\
\text { - take other's work with our } \\
\text { mentioning the name } \\
\text { - steal other's work and saying it } \\
\text { is your work } \\
\text { - refer to me work I did not do }\end{array}$ \\
\hline Advanced Understanding & $25 \%$ & $\begin{array}{l}\text { - ethical concerns } \\
\text { - copyright issues } \\
\text { - writer's intent }\end{array}$ \\
\hline
\end{tabular}

\section{Informants' Ways of Applying Their Understanding of Plagiarism}

Informants were asked to apply their understandings of plagiarism by reading and responding to several scenarios. They were asked to determine if the particular scenario was a form of plagiarism, state why or why not, and then, if considered plagiarism, determine the severity of the act by stating it is not serious at all, moderately or very serious. Chi-square was again used to assess if there were significant differences between 2 nd/3rd-year students and senior (4th year) students regarding assessing the six scenarios. The students were asked to indicate if they thought the scenario represented plagiarism as well as the "degree" of plagiarism displayed in each of the 6 scenarios (specifically in terms of a "Very Serious" example of plagiarism, a "Moderately Serious" example of plagiarism and a "Not Serious" example of plagiarism.) No statistically significant differences were found between the two groups in terms of assessing whether or not the scenarios indicated plagiarism. However, a significant difference was found in terms of the assessment of the seriousness of the plagiarism as presented concerning Scenario five, $\left.X^{2}(2, N=108)=9.426, \mathrm{p}<0.01\right)$.

Table 2 Why Students Plagiarize

Reasons for Academic Plagiarism

Percentage of Inform-

ants

Lack of knowledge in documenting resources

- Inability to express their ideas,

$20 \%$

- Difficulties in developing an opinion in writing,

- Lack of knowledge about writing a research paper or essay,

- Lack of confidence in their writing.

- Lack of time enough to do the research correctly

- Heavy workload for university students.

- Informants state that students often lack the skills needed to engage in the research process. $20 \%$

- This included creativity, brainstorming, finding and organizing resources, paraphrasing skills, data analysis skills, and developing a conclusion. 


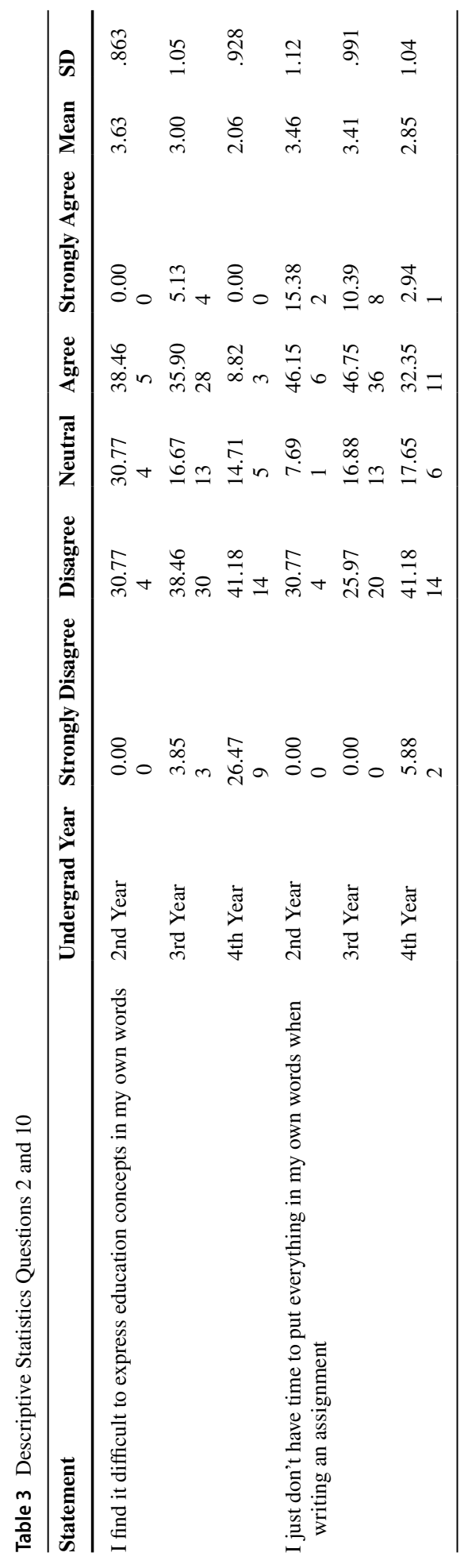


Regarding the open-ended responses to the scenarios (questions 16-31), Fig. 1 illustrates the percentages of students' responses regarding if each hypothetical situation is or is not an act of plagiarism.

Scenarios two, three, and six (see Appendix A for full scenarios) address submitting a peer's essay, copying word-for-word, and submitting work completed from another class. For scenarios two and three, informants reported that $99 \%$ of the students considered the hypotheticals as plagiarism. These students' reasons for plagiarism were clear, it was not the student's work (scenario two), and the student did not document her work (scenario three). Scenario six requires informants to consider if submitting an assignment that they wrote for another class can be submitted to a class if a few minor changes are made. The majority of informants (79\%) argued that this is not plagiarism because this is originally their work; they have ownership of the article, and the work is their ideas. There were $12 \%$ of the responses that did not call this act plagiarism but instead framed submitting the same assignment as "cheating," "cheating the instructor," and breaking a university rule. The remaining 9\% declared they did not know.

Scenarios one and five dealt with using quotation marks, references, and paraphrasing. Scenario one and missing quotation marks, a little over half considered plagiarism, since the writer did not acknowledge that this was a quote that misled the reader. Of the respondents indicating this as plagiarism, eight percent questioned the writer's intent and motives. Those considering it as not plagiarism supported their position with the arguments such as the writer may have made a mistake in the citation but provided the author's name and date, so there was no intention to plagiarize. Concerning paraphrasing, in scenario five, the large majority (85\%) stated that the reason for plagiarism is the lack of documentation and presenting others' work as your own. However, $15 \%$ of the informants did not consider this as plagiarism or, at least, not a severe form of plagiarism because the author did not copy it directly but rewrote it in her own words. An important finding was in the severity of the plagiarism. The 4 th year students $(52 \%)$ considered this serious, while only $23 \% 2$ nd $/ 3$ rd year students considered it not a serious issue.

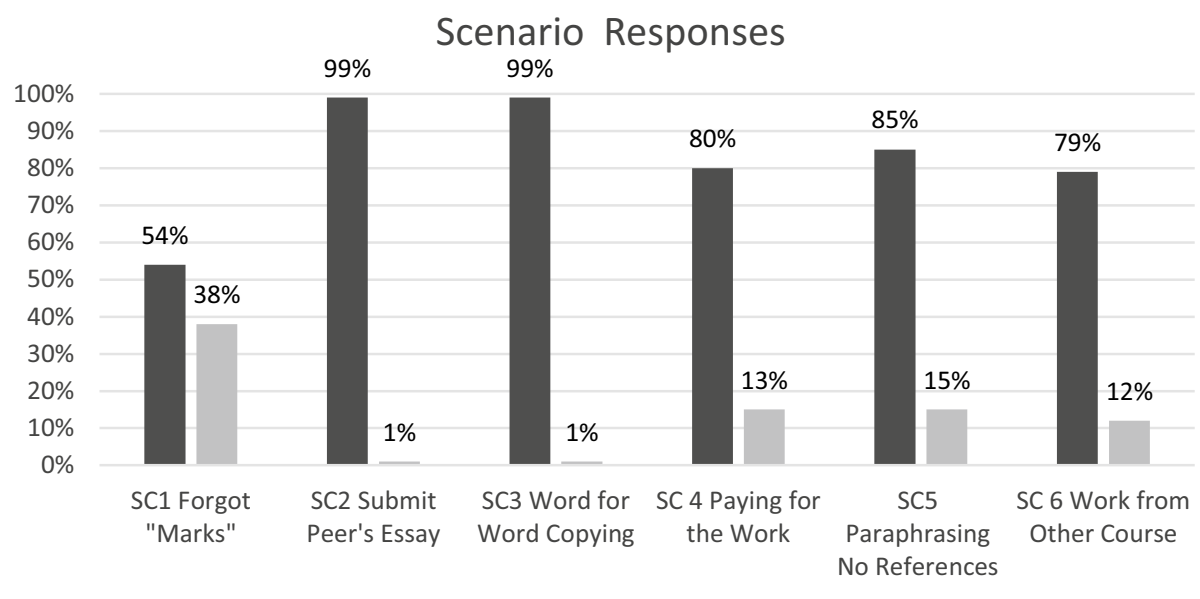

- Plagiarism Not Plagiarism

Fig. 1 Scenario Percentage Responses 
An interesting result is found in scenario four that asks informants to determine if purchasing a paper or paying someone to write an essay or paper for you is acceptable. Those regarding this as plagiarism, $65 \%$ stated that the main reason centered on not doing the work herself. Comments from individual informants such as the student "did not write the paper," "did not put in their own effort," "let someone else do it for her," "it is not her work," "she took someone else's work as her own," and "she used someone's ideas and work as her own" illustrate the majority of the participant's thinking as to why this is plagiarism. Others (15\%) seeing this as plagiarism wrote that this act was "stealing," "cheating," "lying," or "haram" [anything forbidden in Islam]. Students agreed about the seriousness of this action with $53 \%$ of 4 th year and $40 \%$ of 2 nd and 3 rd year students saying this is very serious.

However, $7 \%$ percent of the informants who put forth the idea that since there was a payment, this should not be considered plagiarism with individual comments such as "it is not ethical but isn't consider as a plagiarism because she gave him money regarding his effort;" it is not plagiarism because she paid for it from her own money. It is big an amount sometimes more than 3000 QR" (821 USD), and "it is not plagiarism because they both agree on it, Layla gets the research for paying him the money." Furthermore, 6\% shifted the focus away from the author and assessed if this was plagiarism by considering the work of the individual being paid. Individual informants' comments such as "this action are too dangerous from my point of view because it has lots of negative impact on the student. But I do not know if it is considered plagiarism or not because if they [the paid author] did good work documenting resources, I don't think it is plagiarism;" "because the one who will write it maybe will copy \& paste;" and "it depends on the person if he is using his way in writing or quote from book and another resource."

\section{Discussion}

These findings suggest that a large majority of the informants have a basic understanding of plagiarism that reflect definitions articulated by the university and the College of Education. Some students raise additional issues about plagiarism like intent and ethical issues, demonstrating a more advanced understanding. Studying in a second language plays a role in two key findings, which are discussed below and a specific contextual issue.

First, the significant differences between the groups for items 2 and 10, and the severity of plagiarism are worth some attention, as depicted in responses to scenario 5. When the items are inspected, it would seem reasonable that the 4th year students might more strongly agree with each item statement than the 2nd and 3rd year students. Both of these items have a similar underlying psychological construct of 'experience as a university student' in terms of being better prepared and articulating ideas. Goh (2013) reported that the levels of plagiarism were higher among first-year students than senior students in their 3rd year which seems to be the case in this study. In this context, these Arab students are studying at a university where English is the language of instruction for many programs and courses. These students are second language (L2) writers, and this cultural issue can shed light on plagiarism in this context.

Research has demonstrated that both L1 and L2 novice writers rely on source text excerpts more than their experienced peers (Keck, 2014). However, to better understand this finding as more than merely 4th-year student possessing experience at the university, Pecorari (2015) notes that plagiarism is not just an ethical issue but also a 
learning question. For L2 writers, there are linguistic demands when writing academic texts that students need to perform to read the academic literature and produce written text (Pecorari, 2015). L2 writers need to learn to correctly incorporate and effectively use material from sources in their writing. As indicated by this finding, as students develop their English writing skills, their understanding of plagiarism, and what they consider plagiarism could also mature, possibly reducing plagiarism.

Regarding students and "contract cheating" (Clarke \& Lancaster, 2006) or the purchasing of essays, this is not a new practice and occurs across cultures (Hosny \& Shameem, 2014; Rigby et al., 2015). This current study and Hosny and Shameem (2014) examined female students who are segregated, and almost all are native Arabic speakers who are more comfortable using Arabic their first language rather than English, their second or sometimes third language. Both universities offer programs and courses in English. Hosny and Shameem (2014), reported that $21.62 \%$ of students had previously paid for someone to do an assignment. In this study, some informants (13\%) did not consider payment for a paper as plagiarism, arguing that the individual paid for the work, used her own money, and the person receiving payment did good work and documented resources. These informants had basic understandings of plagiarism, yet it seems unusual that some struggle to determine if contract cheating is considered plagiarism and provide justification.

Additional information could provide insight into students who do not consider buying essays as plagiarism. First, Rigby et al. (2015) reported that students who have English as an additional language are more likely to purchase assignments. Students in this study are native Arabic speakers with English as an additional language. Also, these students listed some of that the reasons for plagiarism as having difficulty expressing ideas in their own words and the lack of time to put everything in their own words. These elements could possibly explain the acceptance of contract cheating. Another perspective that may shed light on students' thinking is the issue of ownership. Hosny and Shameem (2014) found that "Saudi female students feel that if they paid someone to write a paper, they become its owner/author, essentially 'buying' the rights" (as cited in Nash, 2018, p. 5). By purchasing someone's assistance and paying based on a mutually decided agreement, the external help seems to be deemed acceptable behavior. Based on the above, one could infer that these writing challenges that students face and communicating in a non-native language, coupled with the perspective of purchasing ownership, could influence their views on and decisions about contract cheating.

Finally, another contextual issue worth mentioning is that this study was conducted in an Islamic nation where the vast majority of students are Muslims. Although there were limited direct references to religion in this study, other studies have reported that Muslim students considered cheating and dishonesty as unacceptable in Islam, yet still reported academic dishonesty as relatively acceptable (Hosny \& Shameem, 2014; Moten, 2014); Nash, 2018; Razek, 2014). To gain some insight, it is important not to consider Islam or religion as a single dimension in students' understandings of plagiarism. Parboteeah, Hoegel, and Cullen (2008) suggest religiosity, unlike religion, internalizes beliefs and uses those beliefs morally and ethically in the way one lives. Williams (2018) studied students on large, medium, and small private Christian college campuses in the southeastern United States and reported that "students with high levels of religiosity tended to have a lower propensity to cheat, whereas those students with low levels of religiosity tended to have a higher propensity to cheat" (p. 90). Mustapha et al. (2016) argue that "the main consequence of high levels of religiosity is, it can lower the rate of deviant behavior such as in academic" (p. 392). Therefore, when considering the role religion plays in views of 
plagiarism, religiosity should be considered since this could be among many factors that influence one's thinking about wrongdoings.

\section{Conclusion}

Prompted by the notion that preservice teachers need a comprehensive understanding of plagiarism since they will be the future gatekeepers of academic integrity, this paper sampled preservice teachers in one university in a GCC country. Questions were asked centered on various dimensions of plagiarism coupled with several scenarios that solicited informants to determine if an action was plagiarism and the severity of the behavior. The findings raised issues about the influences studying and writing in a second language may have on plagiarism, such as experience at the university and concerns about contract cheating. The issue of religiosity and the internalizing of beliefs were discussed to provide insight into this Islamic context.

There are several limitations to this study. Students self-reporting to determine their knowledge and of plagiarism is a limitation. Although informants might strongly agree that they understand plagiarism and related concepts, their self-perception could be incorrect. Concerns about honesty and self-image might also influence their answers. The sample size was relatively small, and for several contextual reasons, students were not asked if they committed plagiarism. Despite these limitations, these findings should encourage further research in universities in the Arabian Peninsula.

\section{Appendix A}

\section{Survey Questions}

1. What is your gender?

Male

Female

2. Are you currently:

First year undergraduate

Second year undergraduate

Third year undergraduate

Fourth year undergraduate

3. Please write your understanding of the concept plagiarism.

4. Have you read the undergraduate handbook about plagiarism?

Yes

No

Yes, but I don't remember much

5. Why do you think some students plagiarize?

6. I know how to provide references for citations and quotations in my written work

Strongly Disagree

Disagree

Neutral 
Agree

Strongly Agree

7. I find it difficult to express education concepts in my own words

Strongly Disagree

Disagree

Neutral

Agree

Strongly Agree

8. When writing an assignment, I begin by thinking about what I want to say, and then look for evidence relating to that

Strongly Disagree

Disagree

Neutral

Agree

Strongly Agree

9. I know how to show which parts of my assignments were not written by me

Strongly Disagree

Disagree

Neutral

Agree

Strongly Agree

10. Writing an education assignment is all about finding material in books, journals and the Internet and arranging it in the form of an essay

Strongly Disagree

Disagree

Neutral

Agree

Strongly Agree

11. I know what it means to express a concept or idea in my own words

Strongly Disagree

Disagree

Neutral

Agree

Strongly Agree

12. I am afraid that what I write myself about education will look weak and unimpressive

Strongly Disagree

Disagree

Neutral

Agree

Strongly Agree

13. I get higher marks by writing more of my assignment in my own word

Strongly Disagree

Disagree

Neutral

Agree.

Strongly Agree

14. I am confident that when I write something about education it will look impressive

Strongly Disagree

Disagree 
Neutral

Agree.

Strongly Agree

15. I just don't have time to put everything in my own words when writing an assignment Strongly Disagree

Disagree

Neutral

Agree.

Strongly Agree

16. Maha copies a sentence directly from a journal article into her assignment. She writes the name of the author and date of publication in brackets after the sentence but does not include quotation marks or a page number.

Yes

No

Not Sure

17. Why is this or is not plagiarism?

18. If you consider this plagiarism, how serious do you think this is?

Not Serious at all

Moderately Serious

Very Serious

19. Sara has to write an essay for an education subject. She knows that her friend Haya did the exact same essay last year. Sara asks Haya if she can use her essay. Haya agrees, so Sara copies Haya's assignment and hands it in as her own.

Yes

No

Not Sure

20. Why is this or is not plagiarism?

21. If you consider this plagiarism, how serious do you think this is?

Not Serious at all

Moderately Serious

Very Serious

22. Mariam copies word for word information from a book. She does not put the information in quotation marks. She also does not write the author, date of publication or page number at the end of the copied material.

Yes

No

Not Sure

23. Why is this or is not plagiarism?

24. If you consider this plagiarism, how serious do you think this is?

Not Serious at all

Moderately Serious

Very Serious

25. Layla has to write an essay for her education class. She finds a website on the Internet where she can pay someone to write it for her. She pays the money and is emailed the essay. She hands the essay in as her own.

Yes

No

Not Sure

26. Why is this or is not plagiarism? 
27. If you consider this plagiarism, how serious do you think this is?

Not Serious at all

Moderately Serious

Very Serious

28. Noor reads some information from a book. She then paraphrases (or puts the information into her own words) the information and puts it into her assignment without acknowledging where the information came from.

Yes

No

Not Sure

29. Why is this or is not plagiarism?

30. If you consider this plagiarism, how serious do you think this is?

Not Serious at all

Moderately Serious

Very Serious

31. You notice that a paper assignment in your class is just like one you wrote for another class. You change the cover sheet and a few sentences in the introduction and turn it in. This is okay because it is your own work, right?

Yes

No

Not Sure

32. Why is this or is not plagiarism?

33. If you consider this plagiarism, how serious do you think this is?

Not Serious at all

Moderately Serious

Very Serious

Acknowledgements Open Access funding provided by the Qatar National Library.

Data Availability No Intellectual property/ university confidentiality issues.

\section{Declarations}

Conflict of Interest The author declares that he has no competing interests.

Open Access This article is licensed under a Creative Commons Attribution 4.0 International License, which permits use, sharing, adaptation, distribution and reproduction in any medium or format, as long as you give appropriate credit to the original author(s) and the source, provide a link to the Creative Commons licence, and indicate if changes were made. The images or other third party material in this article are included in the article's Creative Commons licence, unless indicated otherwise in a credit line to the material. If material is not included in the article's Creative Commons licence and your intended use is not permitted by statutory regulation or exceeds the permitted use, you will need to obtain permission directly from the copyright holder. To view a copy of this licence, visit http://creativecommons.org/licenses/by/4.0/. 


\section{References}

Adiningrum, T. S., \& Kutieleh, S. (2011). How different are we? Understanding and managing plagiarism between east and west. Journal of Academic Language \& Learning, 5(2), A88-A98.

Ashworth, P., Bannister, P., \& Thorne, P. (1997). Guilty in whose eyes? University students' perceptions of cheating and plagiarism in academic work and assessment. Studies in Higher Education, 22(2), 187-203.

Ashworth, P., Freewood, M., \& Macdonald, R. (2003). The student lifeworld and the meanings of plagiarism. Journal of Phenomenological Psychology, 34(2), 257-278. https://doi.org/10.1163/ 156916203322847164

Asunka, S. (2012). Helping students avoid plagiarism in online courses: A design-based education approach. In K. Beycloglu (Ed.), Ethical technical use, policy and reaction in educational settings (pp. 256-273). IGI Global: Hershey, PA.

Avoiding Plagiarism: Scenarios (2015). Leland speed library, Mississippi College: Clinton, MS. http:// mc.libguides.com/plagiarism/scenarios

Ayub, N., Norizan, Kassim, M. \& Zain, M. (2014). Modernization without westernization: The Kingdom of Saudi Arabia. In Bryan, C. (Ed.), Transcultural Marketing for Incremental and Radicalization (pp. 298-315). IGI Global: Hershey, PA. https://doi.org/10.4018/978-1-4666-4749-7.ch014

Ballantine, J., Guo, X., \& Larres, P. (2015). Psychometric evaluation of the Student Authorship Questionnaire: a confirmatory factor analysis approach. Studies in Higher Education, 40(4), 596-609. https://doi.org/10.1080/03075079.2013.835910

Bakhtiyari, K., Salehi, H., Embi, M. A., Shakiba, M., Zavvari, A., Shahbazi-Moghadam, M. Ebrahim, N. A. \& Mohammadjafari M. (2014). Ethical and unethical methods of plagiarism prevention in academic writing. International Education Studies, 7(7), 52-62.

Boone, H. N. \& Boone, D. A. (2012). Analyzing likert data. Journal of Extension [On-line]. 50, (2). Article 2TOT2. http://www.joe.org/joe/2012april/tt2p.shtml

Breen, L, Maassen M (2005). Reducing the incidence of plagiarism in an undergraduate course: The role of education. Issues in Educational Research, 15(1), 1-16. http://iier.org.au/iier15/breen.html

Chapman, K. J., \& Lupton, R. A. (2004). Academic dishonesty in a global educational market: A comparison of Hong Kong and American university business students. The International Journal of Education Management, 18(7), 425-435.

Cheung, K. Y. F., Stupple, E. J. N., \& Elander, J. (2017). Development and validation of the Student Attitudes and Beliefs about Authorship Scale: a psychometrically robust measure of authorial identity. Studies in Higher Education, 42(1), 97-114. https://doi.org/10.1080/03075079.2015.1034673

Chen, T. \& Ku, N. K. T. (2012). Preservice and in-service teachers' understanding of and perspectives on plagiarism. In P. Resta (Ed.), Proceedings of Society for Information Technology \& Teacher Education International Conference 2012 (pp. 3570-3573). Chesapeake, VA: Association for the Advancement of Computing in Education (AACE).

Chien, S. (2014). Cultural constructions of plagiarism in student writing: Teacher's perceptions and responses. Research in the Teaching of English, 49(2), 120-140.

Cinali, G. (2016). Middle Eastern Perspectives of Academic Integrity: A View from the Gulf Region. In T. Bretag (Ed.), Handbook of Academic Integrity (pp. 113-133). Springer Singapore. https://doi.org/10. 1007/978-981-287-098-8_8

Choo, T. E. \& Paull, M. (2013). Reducing the prevalence of plagiarism: A model for staff, students and universities. Issues in Educational Research, 23(2), 283-298

Chun-Hua, L. S., \& Ling-Yu, W. M. (2007). Academic dishonesty in higher education - A nationwide study in Taiwan. Higher Education, 54(1), 85-97.

Clarke, R., Lancaster, T. (2006). Eliminating the successor to plagiarism? Identifying the usage of contract cheating sites. In: Proceedings of the 2nd International Plagiarism Conference, Gateshead, UK.

Cohen, L., Manion, L., \& Morrison, K. (2007). Research methods in education (6th ed.). Oxford, UK: Routledge Publishers.

Duff, A. H., Rogers, D. P., \& Harris, M. B. (2006). International engineering students-avoiding plagiarism through understanding the Western academic context of scholarship. European Journal of Engineering Education, 31(6), 673-681.

Egan, V. (2008). A cross-cultural and cross-gender comparison of attitudes towards plagiarism: The case of Malaysian and Australian business students. Asian Forum on Business Education, 1(1), 19-33.

Eret, E., \& Ok, A. (2014). Internet plagiarism in higher education: tendencies, triggering factors and reasons among teacher candidates. Assessment \& Evaluation in Higher Education, 39(8), 10021016. https://doi.org/10.1080/02602938.2014.8807762014.880776 
Farisi, M. I. (2013). Academic dishonesty in distance higher education: challenges and models for moral education in the digital era. Turkish Online Journal of Distance Education, 14(4), 176-195.

Fawley, N. E. (2007). Plagiarism Pitfalls: Addressing Cultural Differences in the Misuse of Sources. International Journal of Learning, 14(7), 71-74.

Gibaldi, J. (2003). MLA handbook for writers of research papers (6th ed.). New York: MLA.

Gilbert, F. J., \& Denison, A. R. (2003). Research misconduct. Clinical Radiology, 58(7), 499-504.

Goh, E. (2013). Plagiarism Behavior Among Undergraduate Students in Hospitality and Tourism Education. Journal of Teaching in Travel \& Tourism, 13(4), 307-322. https://doi.org/10.1080/15313220.2013. 839295

Graham, M. A., Monday, J., O’Brien, K., \& Steffen, S. (1994). Cheating at small colleges: An examination of student and faculty attitudes and behaviors. Journal of College Student Development, 35(4), 255-260.

Gullifer, J., \& Tyson, G. A. (2010). Exploring university students' perceptions of plagiarism, A focus group study. Studies in Higher Education, 35(4), 463-481.

Gullifer, J., \& Tyson, G. A. (2014). Who has read the policy on plagiarism? Unpacking students' understanding of plagiarism. Studies in Higher Education, 39(7), 1202-1218. https://doi.org/10. 1080/03075079.2013.777412

Habibzadeh, F., \& Shashok, K. (2011). Plagiarism in scientific writing: words or ideas. Croatian Medical Journal, 52(4), 576-577. https://doi.org/10.3325/cmj.2011.52.576

Hamdan A, A. K., Hussain, Y. I., \& Al-hattami, A. A. (2018). Plagiarism in Saudi Arabian public higher education: Reasons and solutions. Asian Journal of Arts, Humanities and Social Studies, 1(1), 40-48. www.ikprress.org/index.php/AJAHSS/article/view/4219

Hansen, B. (2003). Combating plagiarism. CQ Researcher, 13(32), 773-796.

Harris, R. (2000). Anti-plagiarism strategies for research papers. Costa Mesa: CA: Vanguard University. http://www.sccu.edu/faculty/R_Harris/antiplag.htm

Hafernik, J., Messerschmitt, D., \& Vandrick, S. (2002). Ethical issues for ESL faculty: Social justice in practice. Mahwah, NJ: Lawrence Erlbaum Associates Inc.

Heitman, E., \& Litewka, S. (2011). International perspectives on plagiarism and considerations for teaching international trainees. Urologic Oncology, 29(1), 104-108. https://doi.org/10.1016/j.urolono.2010.09.014

Hofstede, G. (2011). Dimensionalizing cultures: The Hofstede model in context. Online Readings in Psychology and Culture, 2(1), 1-26. https://doi.org/10.9709/2307-0919-1014

Hosny, M., \& Shameem, F. (2014). Attitude of Students Towards Cheating and Plagiarism: University Case Study. Journal of Applied Sciences, 14(8), 748-757. https://doi.org/10.3923/jas.2014.748.757

Howard, R. M. (1995). Plagiarism, authorships and the academic death penalty. College English, 57(7), $788-806$.

Howard, R. M. (2007). Understanding internet plagiarism. Computers and Composition, 24, 3-15.

Ison, D. C. (2014). Does the online environment promote plagiarism? A comparative study of dissertations from brick-and-mortar versus online institutions. Merlot Journal of Online Learning and Teaching, 10(2), 272-282.

Jackson, P. (2006). Plagiarism instruction online: Assessing undergraduate students' ability to avoid plagiarism. College \& Research Libraries, 67(5), 418-428.

Jereb, E., Perc, M., Lämmlein, B., Jerebic, J., Urh, M., Podbregar, I., \& Šprajc, P. (2018). Factors influencing plagiarism in higher education: A comparison of German and Slovene students. PLoS ONE, 13(8), 1-16.

Keck, C. (2014). Copying, paraphrasing, and academic writing development: A re-examination of L1 and L2 summarization practices. Journal of Second Language Writing, 25, 4-22.

Kinder, J., \& Elander, J. (2012). Dyslexia, authorial identity, and approaches to learning and writing: a mixed methods study. British Journal of Eductional Psychology, 82(2), 289-307. https://doi.org/10. 1111/j.2044-8279.2011.02026.x

Lahur, A. M. (2004). Plagiarism among Asian students at an Australian university offshore campus: Is it a cultural issue? A pilot study. http://www.herdsa.org.au/wp-content/uploads/conference/2004/ PDF/A033-jt.pdf

Lim, V. K., \& See, S. K. (2010). Attitudes toward, and intentions to report academic cheating among students in Singapore. Ethics \& Behavior, 11(3), 261-274.

Ma, H. J., Wan, G., \& Lu, E. Y. (2008). Digital cheating and plagiarism in schools. Theory into Practice, 47(3), 197-203.

Madray, A. (2007). Developing Students' Awareness of Plagiarism: Crisis and Opportunities. Library Philosophy and Practice (e-journal). 134. https://digitalcommons.unl.edu/libphilprac/134

Maguire, M., Reynolds, A. E., \& Delahunt, B. (2013). Self-efficacy in academic reading and writing, authorial identity and learning strategies in first- year students, 5(1), 18. 
Martin, B. R. (2013). Whither research integrity? Plagiarism, self-plagiarism and coercive citation in an age of research assessment. Research Policy, 42(5), 1005-1014.

Maxel, O. J. M. (2013). Plagiarism: The cancer of East African university education. Journal of Education and Practice, 4(17), 137-143.

Maxwell, A., Curtis, G. J., \& Vardanega, L. (2008). Does culture influence understanding and perceived seriousness of plagiarism? International Journal for Educational Integrity, 4(2), 25-40.

McCabe, D. L. (2005). Levels of cheating and plagiarism remain high. http://www.waunakee.k12.wi.us/hs/ departments/lmtc/Assignments/McConnellScenarios/AcadHonesty_5Article.pdf

McCabe, D. L., \& Feghali, T. H. (2008). Academic dishonesty in Middle East individual and contextual factors. Research in Higher Education, 49(5), 451-467.

McCuen, R. H. (2008). The plagiarism decision process: The role of pressure and rationalization. IEEE Transactions on Education, 51(2), 152-156. https://doi.org/10.1109/TE.2007.904601

McDonnell, K. E. (2004). Academic plagiarism rules and ESL learning-mutually exclusive concepts? http:// www.american.edu/cas/tesol/resources/working-paper-2.cfm

Menezes, R. G., Giri, S., Pant, S., Kharoshah, M. A., Madadin, M., \& Nagaraja, S. B. (2014). Publication Ethics. Medico-Legal Journal, 82(4), 155-158. https://doi.org/10.1177/0025817214526524

Moten, A. R. (2014). Academic dishonesty and misconduct: Curbing plagiarism in the Muslim world. Intellectual Discourse, 22(2), 167-189 http://irep.iium.edu.my/45425/1/Academic_dishonesty_2014.pdf2014.pdf

Mustapha, R., Hussin, Z., Siraj, S., \& Darusalam, G. (2016). Does Islamic religiosity influence the cheating intention among Malaysian Muslim students? A modified Theory of Planned Behavior International Journal of Academic Research in Business and Social Sciences, 6(12), 389-406. https://doi.org/10. 6007/IJARBSS/v6-i12/2504

Nash, J. (2018). Plagiarism, culture, the Middle East and Westernization: A mixed methods study. Learning and Teaching in Higher Education: Gulf Perspectives, 15(1). https://doi.org/10.18538/lthe.v15.n1.287

Nuriddin, A. (2019). Academic dishonesty among Saudi preparatory year program students: Their perceptions and suggestions to promote academic integrity. (Doctoral dissertation). Northcentral University.

Parboteeah, K. P., Hoegl, M., \& Cullen, J. B. (2008). Ethics and religion: An empirical test of a multidimensional model. Journal of Business Ethics, 80, 387-398. https://doi.org/10.1007/s10551-007-9439-8

Pennycook, A. (1996). Borrowing others' words. TESOL Quarterly, 30(2), 201-230.

Pecorari, D. (2003). Good and original: Plagiarism and patchwriting in academic second language writing. Journal of Second Language Writing, 12(4), 317-345.

Pecorari, D. (2015). Plagiarism, International Students and the Second-Language Writer. In T. Bretag (ed.) Handbook of Academic Integrity (pp. 1-11). Singapore: Springer Science and Business Media. https:// doi.org/10.1007/978-981-287-079-7_69-2

Pittam, G., Elander, J., Lusher, J., Fox, P., \& Payne, N. (2009). Student beliefs and attitudes about authorial identity in academic writing. Studies in Higher education, 34(2), 153-170.

Pupovac, V., Bilic-Zulle, L., \& Petrovecki, M. (2008). On academic plagiarism in Europe. An analytical approach based on four studies. Digithum, O(10). https://doi.org/10.7238/d.v0i10.507

Razek, N. (2014). Academic integrity: A Saudi student perspective. Counselor Education and Human Services Faculty Publications. Paper 3. http://ecommons.udayton.edu/edc_fac_pub/3

Riasati, M. J., \& Rahimi, F. (2013). Why do Iranian postgraduate students plagiarize? A qualitative investigation. Middle East Journal of Scientific Research, 14(3), 309-317.

Rigby, D., Burton, M., Balcombe, K., Bateman, I., \& Mulatu, A. (2015). Contract cheating \& the market in essays. Journal of Economic Behavior \& Organization, 111, 23-37. https://doi.org/10.1016/j.jebo.2014. 12.019

Risquez, A., O’Dwyer, M., \& Ledwith, A. (2013). Thou shalt not plagiarise': from self-reported views to recognition and avoidance of plagiarism. Assessment \& Evaluation in Higher Education, 38(1), 34-43.

Roig, M. (1999). When college students' attempts at paraphrasing become instances of potential plagiarism. Psychological Reports, 84(3), 973-982.

Scanlon, P. M. (2003). Student online plagiarism: How do we respond? College Teaching, 51(4), 161-165.

Scanlon, P. M., \& Neumann, D. R. (2002). Internet Plagiarism among college students. Journal of College Student Development, 43(3), 374-385.

Schrimsher, R. H., Northrup, L. A., \& Alverson, S. P. (2011). A survey of Samford University students regarding plagiarism and academic misconduct. International Journal for Educational Integrity, 7(1), 3-17.

Seven, M. A., \& Engin, A. O. (2008). Faculty of education students' cheating felt needs and reasons. Journal of Atatürk University Social Sciences Institute, 11(1), 111-136.

Stappenbel, B., Rowles, C. \& May, E. (2009). Cultural influence on attitudes to plagiarism In Teaching and Learning for Global Graduates. Proceedings of the 18th Annual Teaching Learning Forum, Jan 29-30. Curtin University of Technology, Perth, Australia. 
Szabo, A., \& Underwood, J. (2004). Cybercheats: Is information and communication technology fueling academic dishonesty?". Active Learning in Higher Education, 5(2), 180-199.

Teixeira, A., \& Rocha, M. (2010). Cheating by economics and business undergraduate students: An exploratory international assessment. Higher Education, 59(6), 663-701.

Torres-Diaz, J. C., Duart, J. M., \& Hinojosa-Becerra, M. (2018). Plagiarism, Internet and Academic Success at the University. Journal of New Approaches in Educational Research, 7(2), 98-104. https:// doi.org/10.7821/naer.2018.7.324

Williams, L. S. (2018). Academic integrity: A correlational study of private Christian college students' religiosity and the propensity to cheat. (Doctoral dissertation). Liberty University.

Yeo, S. (2007). First-year university science and engineering students' understanding of plagiarism. Higher Education Research \& Development, 26(2), 199-216.

Zobel, J., \& Hamilton, M. (2002). Managing student plagiarism in large academic departments. Australian University Review, 45(2), 23-30.

Publisher's Note Springer Nature remains neutral with regard to jurisdictional claims in published maps and institutional affiliations. 